\title{
STUDIES ON INTESTINAL CHOLESTEROL ABSORPTION IN THE HUMAN
}

\author{
By BENGT BORGSTRÖM \\ (From the Department of Physiological Chemistry, University of Lund, Lund, \\ Sweden)
}

(Submitted for publication June 15, 1959; accepted February 5, 1960)

While the main part of our dietary fat, the glycerides, are absorbed with an efficiency of around 99 per cent, the small amount of cholesterol normally dissolved therein is absorbed to a much lesser extent. Results of balance studies in man have shown that the extent of absorption varies widely with the amount fed and the methods used for determining fecal steroids (1). The total capacity of the human intestine to absorb cholesterol has been determined to be around 3 g per day (2). Experiments with labeled cholesterol fed in a single dose have given absorption figures generally even lower than those obtained from balance studies. Thus Biggs and colleagues (3) reported that of 856 and $688 \mathrm{mg}$ tritium-labeled cholesterol, dissolved in oil, emulsified in milk and fed to humans, only 13 and 43 per cent, respectively, were absorbed. Feeding tracer doses of $\mathrm{C}^{14}$-labeled cholesterol (10 to $20 \mathrm{mg}$ ) dissolved in oil, Hellman and associates (4) reported absorption figures of 73 to 89 per cent, and after feeding $1 \mathrm{~g}$ of labeled cholesterol, 52 per cent.

The incomplete absorption of dietary cholesterol compared with dietary glycerides indicates a separation of these compounds during digestion and absorption. A better knowledge of this process might shed light on the mechanism of cholesterol absorption and prompted the series of experiments to be reported in this paper.

Samples of small intestine content were collected after feeding a test meal containing $\mathrm{C}^{\mathbf{1 4}}$ cholesterol to adult human beings intubated with a polyvinyl tubing. The specific activity of the isolated lipids gave information concerning the relative rate of absorption of cholesterol and glycerides at different levels of the small intestine. The dilution of dietary cholesterol by endogenous cholesterol during the digestion was calculated from the specific activities of the cholesterol of the intestinal contents.

High speed centrifugation separated the in- testinal contents into a creamy top layer and a clear subnatant in an attempt to find out whether or not dietary cholesterol is completely mixed with endogenous cholesterol during the absorption process.

\section{METHODS}

\section{Test meal}

The test meal consisted of a well balanced liquid formula made up of skim milk powder, glucose and corn oil (5). Cholesterol-4-C $\mathrm{C}^{\mathbf{1 4}}$ (obtained from Radiochemical Centre, Amersham, England) was diluted with inactive cholesterol, dissolved in benzene, and appropriate amounts were pipetted into corn oil. After evaporation of the benzene with a stream of nitrogen, the corn oil was homogenized with the skim milk in a Waring blendor. Two different test meals were used containing $5 \mu \mathrm{c}$ of $\mathrm{C}^{14}$-cholesterol and $100 \mathrm{mg}$ (I) and $500 \mathrm{mg}$ (II) of added inactive cholesterol per $1,000 \mathrm{~g}$ test meal. After the addition of the cholesterol the sterol contents of the two test meals as determined by the Sperry-Webb method were 0.17 and $0.63 \mathrm{mg}$ per $\mathrm{ml}$ with specific activities of 33,000 and $8,400 \mathrm{cpm}$ per mg. Test meal I was fed to Subjects A, B and C, and Test meal II to Subjects D and E. In Experiment A-I and A-II, a $400 \mathrm{ml}$ test meal was fed; in the others, $300 \mathrm{ml}$ was given.

\section{Experimental design}

Five adult human beings, aged 21 to 70 years, with no apparent gastrointestinal disorders, were intubated with a polyvinyl tube (ID $2.1 \mathrm{~mm}$ ). The leading end of the tube, equipped with a rubber balloon (made from the last $5 \mathrm{~cm}$ of a condom) containing 2 to $3 \mathrm{ml}$ of mercury, was introduced through the patient's nose; $50 \mathrm{~cm}$ above the balloon, 6 to 7 holes were cut in the tubing over an approximate $10 \mathrm{~cm}$ length. The day after intubation the leading end of the tube was usually well down into the small intestine. The location of the holes in the intestine was measured by the amount of tubing that had passed through the nose, and was confirmed by $\mathrm{X}$-ray after filling the tube with radiopaque material. When the holes reached the desired sampling point the patient took the test meal by mouth. Intestinal content was then collected at the intervals and volumes shown in Table I. Flow was maintained by siphonage at floor level and the intestinal content was collected in flasks and chilled in ice. If more than one experiment 
was performed on a patient the tubing was allowed to proceed and the same procedure was repeated on subsequent days at a lower level of the intestine. Any interference with recirculated cholesterol was not of importance as absorbed cholesterol is highly diluted with the cholesterol pool of the organism (Rosenfeld and Hellman) (6).

In addition to the ingredients listed, the test meal contained a polyethylene glycol (PEG) of a mean molecular weight of 4,000.1 This substance, although highly water-soluble, has been found to be nonabsorbable in the human intestine (5). The amount and concentration of $\mathrm{PEG}$ in each sample of intestinal content therefore serves as a reference figure for calculation of the amount and dilution of the test meal in each sample of intestinal content. The ratio of $\mathrm{PEG}$ content to content of a specific substance in the test meal, compared with the same ratio in each sample of intestinal content, indicates the extent of absorption of this substance from the particular sample of test meal. The intubation technique used does not aspirate all of the intestinal contents passing the level of the holes; the PEG figures obtained show an average recovery of around 23 per cent of the test meal over a four hour period (5). In the calculations made in this paper, it is assumed that the fractions of intestinal contents are representative of the total intestinal contents passing the sampled level.

Extraction of lipids. The total lipids of the intestinal content were extracted in a two-phase system of equal volumes of heptane, ether, ethanol and water as previously reported (7). In this way a 99 per cent or better recovery of sterols is obtained.

Cholesterol. Free and total cholesterol of the total lipids was determined according to Sperry and Webb (8). No fast-reacting steroids were found in intestinal contents. To differentiate between coprostanol and cholesterol the Tschugaeff method (9) was used in one instance.

Free fatty acids. Aliquots of the total lipid were titrated with $0.02 \mathrm{~N}$ aqueous sodium hydroxide with thymol blue as indicator.

Tri-, di- and monoglycerides. Aliquots of the total lipids in benzene solution containing 1 to $3 \mathrm{mg}$ total glycerides were added to columns of silicic acid $(1 \mathrm{~g})$. The triglycerides were eluted with $50 \mathrm{ml}$ benzene, the diglycerides with $100 \mathrm{ml}$ benzene : chloroform, $85: 15$, and the monoglycerides with $50 \mathrm{ml}$ of chloroform. Aliquots of these solutions, generally 2 to $5 \mathrm{ml}$, were used for determinations of glyceride-glycerol according to van Handel and Zilversmit (10).

Polyethylene glycol. PEG concentration of intestinal content was determined essentially according to Hydén (11).

Radioactivity. This was determined on $1 \mathrm{mg}$ aliquots of the total lipids on aluminum plates using a Tracerlab flow counter.

Calculations. Specific activity figures of the cholesterol were calculated from the specific activity of the

1 "Polyglykol A4000," Mo and Domsjö, A. B., Sweden. total lipids and the concentration of total sterol in the total lipids as obtained by the Sperry and Webb method (8). The dilution of dietary cholesterol with endogenous cholesterol was based on this figure and the specific activity of the sterols of the test meal was determined in the same way. Both, therefore, also include the sterols of the corn oil-a fact that does not influence the calculations.

The total amount of endogenous cholesterol secreted during the digestion of a test meal was calculated from the dilution of the dietary cholesterol and the amount of test meal present in each fraction collected as determined from the PEG figures.

\section{Separation of intestinal content by centrifugation}

A sample of intestinal contents, collected from duodenum after feeding a test meal, was subjected to centrifugation according to the following scheme: 1) $600 \mathrm{G}$ for 15 minutes in an International centrifuge ; 2) 10,000 $\mathrm{G}$ maximum for 20 minutes; 3) $45,000 \mathrm{G}$ maximum for 30 minutes ; 4) $144,000 \mathrm{G}$ maximum for 45 minutes (2 to 4 in a Spinco preparative ultracentrifuge). The subnatant fluid was sampled with a syringe and a long needle and analyzed for total lipids, free fatty acids, tri-, di- and monoglycerides and total cholesterol.

Seventeen of the samples of intestinal content collected after feeding a test meal with $\mathrm{C}^{\mathbf{1 4}}$-cholesterol were centrifuged at $60,000 \mathrm{G}$ maximum for 30 minutes, the subnatant fluid analyzed, and its composition compared with that of the intestinal contents before centrifugation.

\section{RESULTS AND DISCUSSION}

Concentration and form of cholesterol in intestinal contents during digestion. The cholesterol of the test meal was in the free form, as was the cholesterol contained in the bile that mixed with the dietary cholesterol during digestion (12).

As can be seen in Table I there is a wide variation in the cholesterol content of the intestinal contents analyzed. As an average, 71 per cent of the total cholesterol of the intestinal contents (mean $=0.34 \mathrm{mg}$ per $\mathrm{ml}$ intestinal content) is in the free form and many samples are found in which all the cholesterol is in the free form. There is no apparent relationship between the amount of cholesterol esterified and the level sampled. Thus in experiment C-II (Table I), at a level of $270 \mathrm{~cm}$ from the nose (lower ileum), 88 per cent of the cholesterol is in the free form.

Dilution of dietary cholesterol by endogenous cholesterol. Since little data existed beforehaì d on cholesterol dilution, two different test meals, varying only in amount of cholesterol, were used in order to find the more suitable concentration. 
When the material had been analyzed it was found that both concentrations were within the desired limit and therefore both have been included.

The specific activity of the cholesterol of the intestinal content has been derived from the specific activity of the total lipids and the cholesterol content as determined by the Sperry-Webb method. This indirect determination of cholesterol specific activity could give erroneous results if the cholesterol were changed during digestion. It is, however, known that coprostanol, the main product of bacterial action on cholesterol, is absent in ileostomy and cecostomy drainage in man (13). In accordance with this we have found no evidence for the presence of coprostanol in samples of in-

TABLE I

Composition of lipids of human small intestine contents obtained after feeding a test meal containing $C^{14}$-cholesterol*

\begin{tabular}{|c|c|c|c|c|c|c|c|c|c|c|}
\hline $\begin{array}{l}\text { Experi- } \\
\text { ment }\end{array}$ & $\begin{array}{l}\text { Site of } \\
\text { collection: } \\
\text { distance } \\
\text { from nose }\end{array}$ & $\begin{array}{l}\text { Period of } \\
\text { collection }\end{array}$ & $\begin{array}{l}\text { Volume of } \\
\text { intestinal } \\
\text { content } \\
\text { collected }\end{array}$ & $\begin{array}{l}\text { Conc. of } \\
\text { PEG; } \\
\text { test meal } \\
=100\end{array}$ & $\begin{array}{c}\text { TF in } \\
\text { intestinal } \\
\text { content }\end{array}$ & $\begin{array}{c}\mathrm{TC} \text { in } \\
\text { intestinal } \\
\text { content }\end{array}$ & $\underset{\substack{\text { intestinal } \\
\text { content }}}{F C \text { in }}$ & $\begin{array}{l}\text { Specific } \\
\text { activity } \\
\text { of TF }\end{array}$ & $\begin{array}{l}\text { Specific } \\
\text { activity } \\
\text { of TC }\end{array}$ & $\begin{array}{l}\text { Dilution } \\
\text { of dietary } \\
\text { cholesterol }\end{array}$ \\
\hline A I & 80 & $\begin{array}{c}\min \\
0-60 \\
60-120 \\
120-180 \\
180-240\end{array}$ & $\begin{array}{r}m l \\
76 \\
68 \\
126 \\
78\end{array}$ & $\begin{array}{r}\% \\
41 \\
37 \\
22 \\
8\end{array}$ & $\begin{array}{c}m g / m l \\
7.4 \\
8.8 \\
11.0 \\
7.7\end{array}$ & $\begin{array}{l}\mathrm{mg} / \mathrm{ml} \\
0.24 \\
0.39 \\
0.18 \\
0.15\end{array}$ & $\begin{array}{c}m g / m l \\
0.11 \\
0.28 \\
0.10 \\
0.07\end{array}$ & $\begin{array}{c}c p m / m g \\
117 \\
95 \\
123 \\
190\end{array}$ & $\begin{array}{c}c p m / m g \\
3,610 \\
2,140 \\
7,500 \\
9,750\end{array}$ & $\begin{array}{r}9.1 \\
15.4 \\
4.4 \\
3.4\end{array}$ \\
\hline B I & 100 & $\begin{array}{c}10-20 \\
20-30 \\
30-40 \\
40-50 \\
50-60 \\
60-120 \\
120-180\end{array}$ & $\begin{array}{l}92 \\
90 \\
28 \\
46 \\
19 \\
53 \\
62\end{array}$ & $\begin{array}{r}28 \\
35 \\
38 \\
39 \\
46 \\
33 \\
4\end{array}$ & $\begin{array}{l}5.2 \\
1.6 \\
1.6 \\
2.8 \\
8.4 \\
9.7 \\
7.2\end{array}$ & $\begin{array}{l}0.59 \\
0.40 \\
\\
0.14 \\
0.20 \\
0.33 \\
0.14\end{array}$ & $\begin{array}{l}0.53 \\
0.26 \\
\\
0.10 \\
0.09 \\
0.21 \\
0.05\end{array}$ & $\begin{array}{l}183 \\
179 \\
160 \\
161 \\
149 \\
160 \\
152\end{array}$ & $\begin{array}{r}1,620 \\
715 \\
\\
3,210 \\
6,260 \\
4,720 \\
7,800\end{array}$ & $\begin{array}{r}20.4 \\
46.2 \\
\\
10.3 \\
5.3 \\
7.0 \\
4.2\end{array}$ \\
\hline A II & 120 & $\begin{array}{c}0-60 \\
60-120 \\
120-180 \\
180-240\end{array}$ & $\begin{array}{r}98 \\
150 \\
75 \\
100\end{array}$ & $\begin{array}{r}48 \\
46 \\
23 \\
8\end{array}$ & $\begin{array}{r}5.0 \\
4.8 \\
19.9 \\
7.3\end{array}$ & $\begin{array}{l}0.25 \\
0.11 \\
0.66 \\
0.19\end{array}$ & $\begin{array}{l}0.25 \\
0.11 \\
0.58 \\
0.18\end{array}$ & $\begin{array}{l}179 \\
162 \\
228 \\
191\end{array}$ & $\begin{array}{l}3,590 \\
7,060 \\
6,880 \\
7,320\end{array}$ & $\begin{array}{l}9.2 \\
4.7 \\
4.8 \\
4.5\end{array}$ \\
\hline C I & 180 & $\begin{array}{r}0-60 \\
60-120 \\
120-180\end{array}$ & $\begin{array}{r}130 \\
23 \\
50\end{array}$ & $\begin{array}{l}34 \\
69 \\
36\end{array}$ & $\begin{array}{l}2.3 \\
2.9 \\
3.3\end{array}$ & $\begin{array}{l}0.10 \\
0.03 \\
0.46\end{array}$ & $\begin{array}{l}0.02 \\
0.03 \\
0.30\end{array}$ & $\begin{array}{l}238 \\
179 \\
179\end{array}$ & $\begin{array}{r}5,470 \\
17,300 \\
1,290\end{array}$ & $\begin{array}{r}6.0 \\
1.9 \\
25.5\end{array}$ \\
\hline C II & 270 & $\begin{array}{c}0-60 \\
60-120 \\
120-180 \\
180-240\end{array}$ & $\begin{array}{l}29 \\
42 \\
60 \\
90\end{array}$ & $\begin{array}{r}78 \\
190 \\
30 \\
16\end{array}$ & $\begin{array}{l}3.2 \\
2.9 \\
5.4 \\
3.2\end{array}$ & $\begin{array}{l}0.69 \\
0.64 \\
0.57 \\
0.69\end{array}$ & $\begin{array}{l}0.67 \\
0.64 \\
0.38 \\
0.59\end{array}$ & $\begin{array}{l}240 \\
240 \\
246 \\
623\end{array}$ & $\begin{array}{l}1,115 \\
1,090 \\
2,330 \\
2,890\end{array}$ & $\begin{array}{l}29.6 \\
30.3 \\
14.2 \\
11.4\end{array}$ \\
\hline D I & 105 & $\begin{array}{c}10-20 \\
20-30 \\
30-40 \\
40-50 \\
50-60 \\
60-120 \\
120-180\end{array}$ & $\begin{array}{r}73 \\
38 \\
38 \\
23 \\
8 \\
47 \\
20\end{array}$ & $\begin{array}{l}28 \\
49 \\
47 \\
59 \\
74 \\
99 \\
36\end{array}$ & $\begin{array}{l}6.7 \\
6.1 \\
2.9 \\
2.6 \\
\\
3.9 \\
3.2\end{array}$ & $\begin{array}{l}0.50 \\
0.06 \\
0.29 \\
0.25 \\
0.26 \\
0.13\end{array}$ & $\begin{array}{l}0.29 \\
0.04 \\
0.05 \\
0.18 \\
0.19 \\
0.05\end{array}$ & $\begin{array}{l}137 \\
217 \\
113 \\
138 \\
\\
268 \\
230\end{array}$ & $\begin{array}{r}1,835 \\
22,100 \\
1,130 \\
1,440 \\
4,030 \\
5,660\end{array}$ & $\begin{array}{l}4.6 \\
\\
7.4 \\
5.8 \\
\\
2.1 \\
1.5\end{array}$ \\
\hline E I & 110 & $\begin{array}{c}10-20 \\
20-30 \\
30-40 \\
40-50 \\
50-60 \\
60-120 \\
120-180 \\
180-240\end{array}$ & $\begin{array}{r}35 \\
26 \\
28 \\
7 \\
11 \\
90 \\
94 \\
71\end{array}$ & $\begin{array}{l}34 \\
46 \\
38 \\
40 \\
51 \\
43 \\
24 \\
32\end{array}$ & $\begin{array}{r}12.1 \\
16.1 \\
9.9 \\
\\
7.8 \\
8.9 \\
11.7 \\
16.7\end{array}$ & $\begin{array}{l}0.66 \\
0.32 \\
0.40 \\
\\
0.15 \\
0.20 \\
0.25 \\
0.40\end{array}$ & & $\begin{array}{l}149 \\
154 \\
172 \\
\\
138 \\
172 \\
170 \\
160\end{array}$ & $\begin{array}{l}2,740 \\
7,750 \\
4,250 \\
\\
7,200 \\
7,650 \\
7,950 \\
6,700\end{array}$ & $\begin{array}{l}3.1 \\
1.1 \\
2.0 \\
\\
1.2 \\
1.1 \\
1.1 \\
1.3\end{array}$ \\
\hline E II & 210 & $\begin{array}{c}0-60 \\
60-120 \\
120-180 \\
180-240\end{array}$ & $\begin{array}{r}9 \\
3 \\
15 \\
20\end{array}$ & $\begin{array}{r}4 \\
13 \\
101 \\
28\end{array}$ & $\begin{array}{l}1.7 \\
1.9 \\
4.1\end{array}$ & $\begin{array}{l}0.26 \\
0.47 \\
0.76\end{array}$ & $\begin{array}{l}0.21 \\
\\
0.47 \\
0.76\end{array}$ & $\begin{array}{r}96 \\
505 \\
585\end{array}$ & $\begin{array}{r}630 \\
2,040 \\
3,160\end{array}$ & $\begin{array}{r}13.3 \\
\\
4.1 \\
2.7\end{array}$ \\
\hline
\end{tabular}

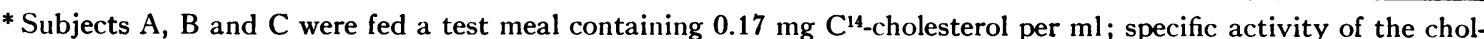

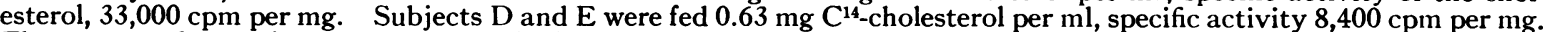
The test meal contained $55 \mathrm{mg}$ per $\mathrm{ml}$ of glyceride as corn oil. $\mathrm{TF}=$ total fat; $\mathrm{TC}=$ total cholesterol; $\mathrm{FC}=\mathrm{free}$ cholesterol. 
TABLE II

Milligrams of endogenous cholesterol secreted to the intestinal contents during digestion of a test meal*

\begin{tabular}{ccc}
\hline \hline Experiment & $\begin{array}{c}\text { Level of sampling: } \\
\text { distance from nose }\end{array}$ & $\begin{array}{c}\text { Amt. of endogenous } \\
\text { cholesterol secreted }\end{array}$ \\
\hline & $c m$ & $m g$ \\
A I & 80 & 560 \\
B I & 100 & 1025 \\
D I & 105 & 556 \\
E I & 110 & 104 \\
A II & 120 & 368 \\
C I & 180 & 440 \\
E II & 210 & 550 \\
C II & 270 & 1275 \\
& & Mean \\
\end{tabular}

* Calculations were based on dilution of dietary cholesterol and amount of test meal in each sample as obtained from the PEG figures. The intestinal content recovered was assumed to be representative for all the intestinal contents passing the level sampled.

The calculations for each sample were made as follows:

1) $\frac{\mathrm{ml} \text { intestinal content } \times \text { conc. } \mathrm{PEG}}{100}$

$=\mathrm{ml}$ test meal in sample

2) $\left[\begin{array}{l}\text { ml test } \\ \text { meal in } \\ \text { sample } \times \text { esterol in } \\ \text { test meal }\end{array} \times \begin{array}{l}\text { dilution of } \\ \text { dietary } \\ \text { cholesterol }\end{array}\right]$

$$
-\underset{\text { in test meal }}{\text { mg cholesterol }}=\underset{\text { cholesterol }}{m g \text { endogenous }}
$$

3) mg endogenous $\mathrm{ml}$ test $\begin{aligned} & \text { molesterol in } \\ & \text { all samples }\end{aligned} \quad \begin{aligned} & \text { meal in the } \\ & \text { samples }\end{aligned} \times \begin{aligned} & \text { ml test } \\ & \text { meal fed }\end{aligned}$

total amount of endo$=$ genous cholesterol during the digestion period.

For example, using figures from Experiment A I (Table I) :

1)

$\begin{array}{rrr}76 & 0.41= & 31 \\ 68 & 0.37 & 25 \\ 126 & 0.22 & 27 \\ 78 & 0.08 & 6 \\ & & \frac{89}{89}\end{array}$

2)

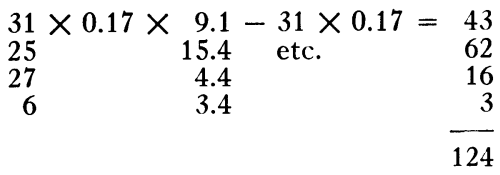

3)

$$
\frac{124}{89} \times 400=560
$$

testinal content as tested by the Tschugaeff method.

The amount of endogenous cholesterol mixed with the test meal during the four hour digestion period has been calculated from the specific activity of the cholesterol of the intestinal contents in relation to that of the test meal, assuming that the sampling is representative of the entire intestinal contents passing that level. The figures obtained from these calculations are given in Table II and range from 104 to $1,275 \mathrm{mg}$, with an average of 610 . No correlation is apparent between the level sampled and the amount of cholesterol secreted during digestion. Figure 1 shows the time course of the dilution of the dietary cholesterol in relation to the color of the intestinal content (as index of the bile admixing) (5), the concentration of the test meal and of total cholesterol in the intestinal content. It is apparent from these data that there is a parallel between bile color and cholesterol dilution in the upper part of the small intestine indicating that the endogenous cholesterol originates mainly from the bile. The present data cannot be directly compared with the figures of 1 to $3 \mathrm{~g}$ for endogenous daily cholesterol secretion determined by Stanley and Cheng (14) from fecal data but they seem to be in reasonable agreement.

A marked feature of the data obtained are the wide variations within different samples collected at one site in one subject over time. An inspec-

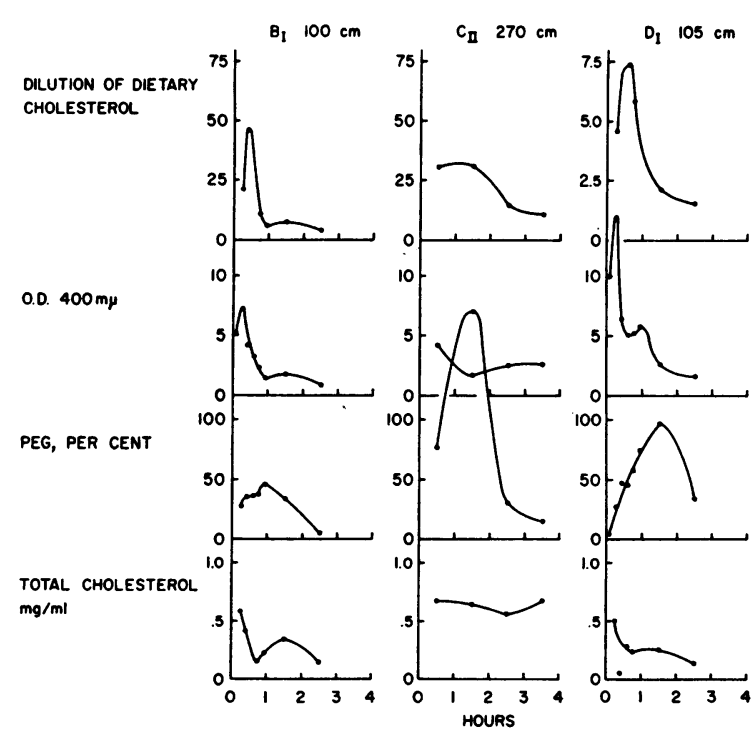

Fig. 1. Time course of dilution of Dietary CholesTEROL WITH ENDOGENOUS CHOLESTEROL DURING DIGESTION AND ABSORPTION OF $\mathrm{C}^{\mathbf{1 4}}$-CHOLESTEROL. Included also are figures for the optical density at $400 \mathrm{~m} \mu$ (as index of bile admixing), the concentration of test meal (as indicated by the concentration of reference substance $=$ PEG) and cholesterol concentration of the intestinal contents. The figures refer to experiments B I, C II and D I in Table I. 


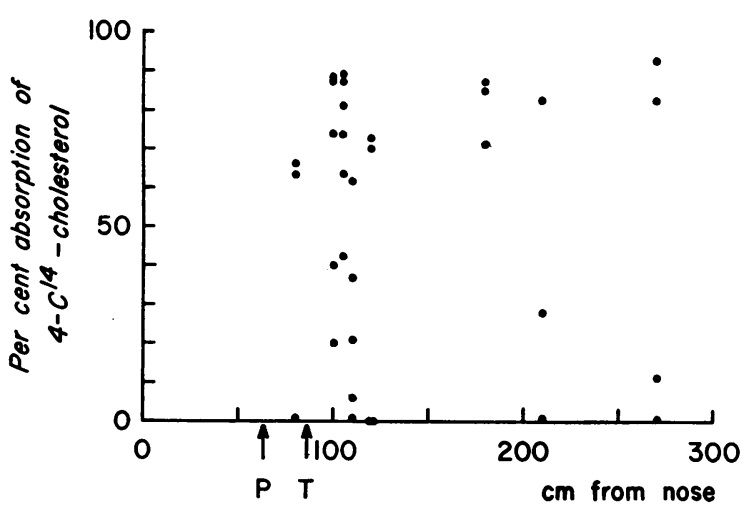

Fig. 2. Site of absorption of Cholesterol OVER the LENGTH OF THE HUMAN SMALL INTESTINE. The levels refer to the experiments in Table $\mathrm{I} . \mathrm{P}=$ pylorus; $\mathrm{T}=$ ligament of Treitz.

tion of Table I shows a variation of total cholesterol content from 0.03 to $0.76 \mathrm{mg}$ per $\mathrm{ml}$, a variability in the percentage of free cholesterol from 17 to 100 , and up to a 24 -fold difference in the dilution of dietary cholesterol by endogenous cholesterol and so forth. The obvious reason for these differences is the complexity of the digestive and absorptive processes. The stomach delivers the test meal in small portions over a period of hours, each portion being treated individually in the intestine, the specific activity and the concentration of cholesterol being dependent upon the relative concentration of test meal and of the digestive secretions mixed with it. From Figure 1 it is clear that the general trend is a high dilution of the dietary cholesterol during the first hour of digestion, concomitant with the emptying of the gall bladder, followed by lesser dilutions of later samples. That the effect of emptying the gall bladder is not so marked on the concentration of cholesterol is obviously due to the simultaneous cholesterol absorption.

Site of absorption of cholesterol. The percentage absorption of the fed $\mathrm{C}^{14}$-cholesterol has been calculated from the $\mathrm{C}^{14}$ activity and the concentration of the reference substance in the different samples of intestinal contents. The data obtained are seen in Figure 2 plotted over the length of the small intestine. The general shape of the curve is the same as that obtained earlier for fat, carbohydrate and protein (5). In some of the samples analyzed the absorption was found to be zero or negative, that is, the sample con- tained more radioactivity per unit PEG than did the test meal. This must be caused by a separation to some extent of the reference substance from the cholesterol in the intestinal lumen, an inevitable error when a water-soluble reference substance is used in combination with a waterinsoluble substance such as cholesterol. This error should be most marked in samples taken at low levels of the intestine. Even if these errors are considered, it is believed that the absorption curve obtained indicates that cholesterol is mainly.absorbed in the first part of the jejunum as are glycerides, protein and carbohydrates (5).

Relative rate of absorption of cholesterol and glycerides. The specific activity of the total lipids recovered from the intestinal contents gives an indication of the relative rate of absorption of glycerides and cholesterol. In practically all samples analyzed it is apparent that the specific activity of the lipids of the intestinal contents is higher than that of the fed lipid mixture. This fact indicates that glycerides and fatty acids are absorbed more rapidly and also more completely than is the cholesterol. If the specific activities of the intestinal lipids are plotted over the length of the small intestine (Figure 3 ) it is apparent that this difference in rate of absorption begins in the upper part of the small intestine and becomes more marked further down in the intestine. A five- to sixfold increase in the specific activity of the total lipids is found in the distal ileum.

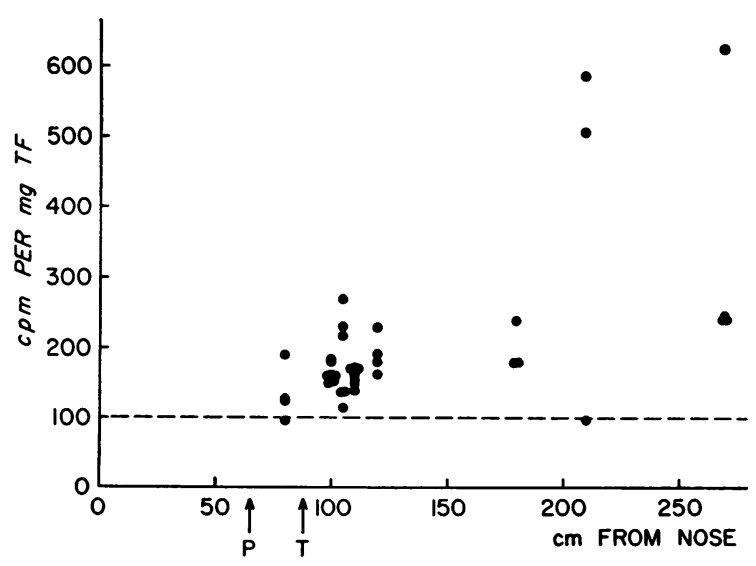

Fig. 3. SPECIFic ACtivities of total Lipids FROM INTESTINAL CONTENTS COLLECTED FROM DIFFERENT LEVELS OF HUMAN SMALl INTESTINE. Specific activity of the total lipids of the test meal $=100: \mathrm{P}=$ pylorus $; \mathrm{T}=$ ligament of Treitz. 
TABLE III

Centrifuged intestinal contents collected from duodenum of a human fed a test meal*

\begin{tabular}{cccccc}
\hline & \multicolumn{3}{c}{ Glyceride } & $\begin{array}{c}\text { Total } \\
\text { chol- } \\
\text { esterol }\end{array}$ & $\begin{array}{c}\text { Free } \\
\text { fatty } \\
\text { acids }\end{array}$ \\
\cline { 2 - 5 } Centrifugation & Tri- & Di- & Mono- & & \\
\hline G max. & & \multicolumn{3}{c}{$\mathrm{mg} / \mathrm{ml}$} \\
0 & 5.5 & 0.66 & 0.34 & 0.26 & 5.4 \\
$600 ; 10$ min. & 0.44 & 0.23 & 0.22 & 0.11 & 2.4 \\
10,$000 ; 20$ min. & 0.28 & 0.23 & 0.20 & 0.09 & 2.0 \\
45,$000 ; 30$ min. & 0.33 & 0.17 & 0.15 & 0.08 & 1.3 \\
144,$000 ; 45$ min. & 0.22 & 0.13 & 0.12 & & 1.1 \\
\hline
\end{tabular}

* Composition of the subnatant solution, $\mathrm{mg}$ per $\mathrm{ml}$.

The mechanism behind the incomplete absorption of cholesterol, compared with glycerides, is not clear. Any significant conversion of cholesterol to the slightly absorbable coprostanol was not evident in our experiments on an intestinal level distal to that in which cholesterol absorption was almost completed. In an attempt to find out if the incomplete absorption of cholesterol could be explained by differences in the physical state of cholesterol and glyceride in the intestinal content, the latter was subjected to high speed separation in a Spinco centrifuge.

Separation of intestinal content by centrifugation. The fact that the emulsified lipids of the test meal could easily be collected by centrifugation as a creamy layer above a lipid-free subnatant led to these experiments. Intestinal contents collected from the upper part of the small intestine after feeding a test meal could also be separated by centrifugation into a top layer and a subnatant which, on analysis, showed differences in composition. As can be seen in Table III the most striking difference is that most of the triglycerides are in the top layer, while the di- and monoglycerides, fatty acids and cholesterol are more evenly distributed in both layers. Results of analysis of a series of subnatant layers obtained by centrifugation of intestinal content from different levels of the gut are found in Table IV.

The subnatant, which in all cases was completely clear, contained on an average 47.8 per cent of the total lipids, 44.1 per cent of the total cholesterol and 43.6 per cent of the radioactive cholesterol. The average specific activity of the cholesterol in the subnatant solution was $3,420 \mathrm{cpm}$ per $\mathrm{mg}$ compared with 3,450 for the cholesterol of the top layer. The identical specific activity of the cholesterol in the two layers indicates that dietary cholesterol and endogenous cholesterol secreted via the bile are completely mixed during digestion. The appearance of the top layer in most samples from the upper part of the intestine was that of large oil droplets, indicating its close relationship to the emulsion of the test meal. Also, the chemical composition showed a predominance of triglycerides while the subnatant contained mostly the more hydrophilic split products of the triglycerides.

The physical state of the lipids in the subnatant clear solution is not known, but the lipids therein must be much more finely dispersed than they are in the emulsion, and are probably of micellar character (15). The formation of a clear lipid containing "solution," corresponding in our experiments to the subnatant after centrifugation,

TABLE IV

Distribution by centrifugation of total lipids, total cholesterol, free cholesterol, free fatty acids (FFA) and $C^{14}$ activity between top layer and subnatant layer*

\begin{tabular}{|c|c|c|c|c|c|c|}
\hline & $\mathrm{TF}$ & FFA & TC & FC & $\begin{array}{l}\text { Specific } \\
\text { activity } \\
\text { of TF }\end{array}$ & $\begin{array}{c}\text { Specific } \\
\text { activity } \\
\text { of TC }\end{array}$ \\
\hline & $m g / m l$ & $\mathrm{mg} / \mathrm{ml}$ & $\mathrm{mg} / \mathrm{ml}$ & $\mathrm{mg} / \mathrm{ml}$ & $c p m / m g$ & $c p m / m g$ \\
\hline Top & 3.5 & 1.2 & 0.19 & 0.15 & 662 & 3,480 \\
\hline Subna & -3.2 & 1.4 & 0.15 & 0.11 & 513 & 3,420 \\
\hline
\end{tabular}

* Intestinal contents from Experiments A I, A II, B I, C I and C II, 60,000 G for 45 minutes; mean of 17 samples analyzed. See Table I for abbreviations.

obviously is an effect of the admixing of bile and the action of the pancreatic lipase generating more hydrophilic products from the dietary triglycerides. It is well known that cholesterol absorption is dependent on bile acids $(16,17)$ and is promoted by fatty acids (18). A possible explanation of the relatively incomplete absorption of cholesterol is that the subnatant solution can dissolve cholesterol only to a certain extent depending upon the concentration of mixed glycerides, fatty acids and bile constituents. When these carrier substances, and especially the bile acids, have been absorbed in the upper part of the intestine, the cholesterol remaining is left in a physical state unavailable for absorption.

\section{SIMMARY}

Cholesterol metabolism during intestinal digestion and absorption has been studied in the 
human by analyzing small intestine contents recovered by intubation after feeding a test meal containing $\mathrm{C}^{14}$-cholesterol. The results can be summarized as follows :

1. The concentration of cholesterol in small intestine contents varied between 0.03 and $0.76 \mathrm{mg}$ per $\mathrm{ml}$ with an average of $0.34 \mathrm{mg}$ per $\mathrm{ml}$.

2. The percentage of free cholesterol varied between 17 and 100 per cent with a mean of 71 per cent.

3. Dilution of dietary cholesterol by endogenous cholesterol during digestion varied widely but seemed to be correlated mainly with the admixture of bile with intestinal contents. The total amount of endogenous cholesterol added during the digestion period ranged from 104 to $1,275 \mathrm{mg}$, with an average of $610 \mathrm{mg}$.

4. The specific activity of the total lipids of the intestinal contents ranged up to five to six times higher than that of the fed lipid mixture, indicating that glyceride and/or its split products are absorbed more rapidly and more completely than is cholesterol.

5. Centrifugation of intestinal content at high speed (above $45,000 \times \mathrm{G}$ ) gave an oily top layer and a clear subnatant of different composition chemically and physically. The isotopic data from these experiments indicated that dietary and endogenous cholesterol are completely mixed during digestion.

The obvious reason for the large variations of data from sample to sample even at the same level in the same experimental subject over time is the complexity of the digestive and absorptive processes, the chyme passing distally in the intestine in small fractions which are individually handled.

\section{REFERENCES}

1. Cook, R. P. Cholesterol; Chemistry, Biochemistry and Pathology. Academic Press, New York, 1958.

2. Ivy, A. C., Karvinen, E., Lin, T. M., and Ivy, E. K. Some parameters of sterol metabolism in man on a sterol- and fat-free diet. J. appl. Physiol. 1957, $11,1$.

3. Biggs, M. W., Kritchevsky, D., Colman, A. B., Gofman, J. W., Jones, H. B., Lindgren, F. T., Hyde, G., and Lyon, T. D. Observations on the fate of ingested cholesterol in man. Circulation 1952, $6,359$.
4. Hellman, L., Rosenfeld, R. S., Eidinoff, M. L., Fukushima, D. K., Gallagher, T. F., Wang, C-I., and Adlersberg, D. Isotopic studies of plasma cholesterol of endogenous and exogenous origins. J. clin. Invest. 1955, 34, 48.

5. Borgström, B., Dahlqvist, A., Lundh, G., and Sjövall, J. Studies of intestinal digestion and absorption in the human. J. clin. Invest. 1957, 36, 1521.

6. Rosenfeld, R. S., and Hellman, L. The relation of plasma and biliary cholesterol to bile acid synthesis in man. J. clin. Invest. 1959, 38, 1334.

7. Ahrens, E. H., Jr., and Borgström, B. Exchange of free fatty acids and glyceride fatty acids during fat digestion in the human intestine. J. biol. Chem. 1956, 219, 665.

8. Sperry, W. M., and Webb, M. J. A revision of the Schoenheimer-Sperry method for cholesterol determination. J. biol. Chem. 1950, 187, 97.

9. Schön, H., and Gey, F. Zur elutionschromatographischen Trennung der freien und veresterten Cholesterins in Argan- und Serumfetten und direkten kolorimetrischen Bestimmung. HoppeSeylers Z. physiol. Chem. 1956, 303, 81.

10. van Handel, E., and Zilversmit, D. B. Micromethod for direct determination of serum triglycerides. J. Lab. clin. Med. 1957, 50, 152.

11. Hydén, S. A. A turbidometric method for the determination of higher polyethylene glycols in biological materials. Ann. Agr. Coll. (Sweden) 1955, 22, 139.

12. Isaksson, B. On the lipid constituents of normal bile. Acta Soc. Med. upsalien. 1951, 56, 177.

13. Gardner, J. A., Gainsborough, H., and Murray, R. M. The distribution of sterols in human faeces; an examination of ileal contents. Biochem. J. 1935, 29, 1139.

14. Stanley, M. M., and Cheng, S. H. Cholesterol exchange in the gastrointestinal tract in normal and abnormal subjects. Gastroenterology 1956, 30, 62.

15. Borgström, B. Studies on pancreatic lipase in Biochemical Problems of Lipids. Proc. 2nd Internatl. Conf., Univ. of Ghent, 1955. G. Popják and E. Le Breton, Eds. London, Butterworth, 1956, p. 179.

16. Chaikoff, I. L., Bloom, B., Siperstein, M. D., Kiyasu, J. Y., Reinhardt, W. O., Dauben, W. G., and Eastman, J. F. $\mathrm{C}^{14}$-cholesterol. I. Lymphatic transport of absorbed cholesterol-4-C ${ }^{14}$. J. biol. Chem. 1952, 194, 407.

17. Vahouny, G. V., and Treadwell, C. R. Changes in lipid composition of lymph during cholesterol absorption in the rat. Amer. J. Physiol. 1957, 191, 179.

18. Pihl, A. The effect of dietary fat on the intestinal cholesterol absorption and on the cholesterol metabolism in the liver of rats. Acta physiol. scand. 1955, 34, 183. 